\title{
La Vida se quedó en el Río Sinú. El Estado, los Embera-Katío de Tierralta y la Represa Urrá I
}

\section{Life stayed on the Rio Sinu. The State, the Embera-Katio of Tierralta and the Urrá I Dam}

\author{
María José Rodríguez González
}

Recepción: 22 de junio de 2017

Aceptación: 23 de agosto de 2107

\begin{abstract}
Resumen
En este artículo se analizará el accionar del Estado con respecto a la construcción de la hidroeléctrica Urrá I, y cómo esto perjudicó los intereses de los Embera-Katío, a nivel cultural, económico y político, que terminaron por afectar la vida de dicho pueblo indígena. A la vez, el artículo pretende cuestionar la teoría del abandono estatal, en las dinámicas del conflicto armado, desplazamiento, la política local y la violación normativa, para identificar el rol del aparato estatal a nivel nacional y regional.

Los actores a analizar son: el Estado (desde su papel en lo local), la clase política y económica (con respecto a sus intereses en la región), el paramilitarismo (desde su funcionamiento, como brazo aliado del Estado y la economía) y la comunidad indígena, analizando la vulneración de sus derechos humanos por la construcción de la represa.

Palabras Claves: Estado, Embera-Katío, conflicto armado, hidroeléctrica y normatividad.

\section{Abstract}

This article will analyze the actions of the State in relation to the construction of the Urrá I hydroelectric power station, and as this damages the interests of the Embera-Katio, cultural, economic and political, that ended up affecting the life of said indigenous people. At the same time, the article seeks to question the theory of state abandonment, in the dynamics of armed conflict, displacement, local politics and normative violation, to identify the role of the state apparatus at national and regional level.

The actors to be analyzed are: the State (from its role in the local), the political and economic class (with respect to its interests in the region), paramilitarism (from its operation, as an allied arm of the State and the economy) and the indigenous community, analyzing the violation of their human rights by the construction of the dam.
\end{abstract}

Key Words: State, Embera-Katío, armed conflict, hydroelectric and normativity. 


\section{Introducción}

\section{Geografia y Economía}

1 departamento de Córdoba perteneciente a la costa colombiana, posee
una de las zonas naturales más significativas del territorio, el Parque
Natural Nudo de Paramillo, en donde se ubica el municipio de Tierralta
y donde habitan los Embera-Katío, cerca de los ríos Sinú, Esmeralda y Verde. Este escenario ha sido de gran relevancia en el desarrollo del conflicto armado por la disputa territorial y las rutas de movilidad del narcotráfico.

\section{Mapa 1.}

\section{Ubicación de los Embera- Katío en el Nudo de Paramillo}

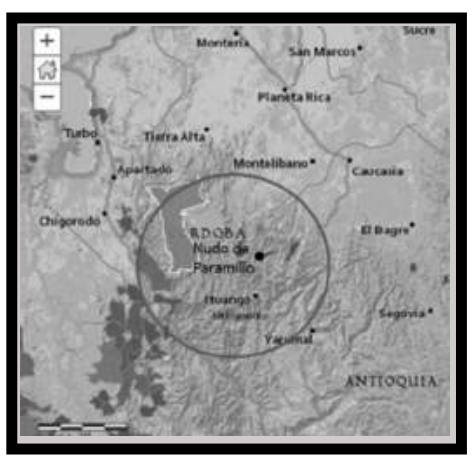

Nombre del Resguardo: Alto Sinú, Esmeralda Cruz Verde e Iwagado. Etnia: Embera - Katío.

Municipio: Tierralta.

Departamento: Córdoba. Área Constituida: 103.517 .50 . Área Ampliada: 12.562.42. Área total: 116.079.92.

Fuente: https://www.arcgis.com Elaborado por: la autora

Tierralta está situado en el extremo sur occidental del departamento. Como se puede observar en el mapa cobija gran parte del Parque Natural Nudo de Paramillo. Ante estas capacidades geográficas que posee el territorio, se ha establecido una economía fuerte, posicionando a distintos actores, de los cuales hacen los ganaderos, los mineros, los comerciantes y los actores armados ilegales. 


\section{Grafico 1.}

Actividades Económicas dentro del PIB de Córdoba

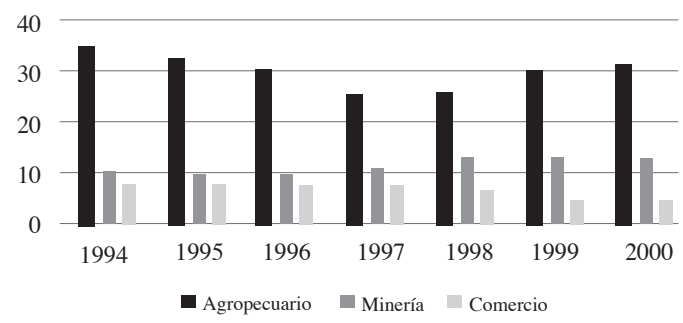

Fuente: Estudios económicos del Banco de la Republica - https://goo.gl/xWpd2L Elaborado por: la autora.

Como se puede observar en la gráfica, las economías más pujantes del territorio están relacionadas con el sector primario y terciario, como lo son: la ganadería y el cultivo referente al sector agropecuario, generando la cría, el levante, la ceba y la comercialización de ganado vacuno mediante grandes extensiones de terreno, generalmente en las llanuras del departamento. Este sector se ha visto envuelto en casos de corrupción, como el caso del Fondo Ganadero de Córdoba. Que en 1997, según prensa nacional, expropió junto con las Autodefensas Unidas más de cien predios de campesinos, para lograr expandir el negocio de la ganadería ${ }^{1}$.

En el sector de la minería, se encuentran los yacimientos de níquel de Cerro Matoso, los cuales han generado procesos de desplazamiento, violación de derechos humanos y normatividad ambiental, con ayuda estatal, para aumentar la prórroga de contaminación y afectación a la población hasta el año 2040.

Otra fuente económica relevante es la madera, la cual se basa en la tala, corte y comercialización. Este trabajo es principalmente realizado por campesinos y empresas extranjeras como la Goerge D. Emery Company

1. Ver www.banrep.gov.co en https://goo.gl/R5KS4c 
de Boston, que a gran escala ha generado la depredación del medio natural boscoso, afectando el ecosistema y a las poblaciones rurales que están rodeadas por la selva, estas dinámicas han beneficiado a las actividades ganaderas y agrícolas, asentándose en la zona selvática para ampliar sus territorios.

En cuanto a la pesca, ésta se ha mantenido de manera artesanal y prácticamente es una labor por subsistencia. Aun así, con el proyecto de la hidroeléctrica Urrá I, se generó un estancamiento del Río Sinú, lo que provocó que los campesinos y los indígenas Embera-Katío, disminuyeran la pesca, generando desplazamiento de los pobladores.

Otro factor que influye en la economía del municipio es la presencia de medianos inversionistas y comerciantes de bienes manufacturados, como fondas, graneros, almacenes, etc., sobre todo por la colonización de los antioqueños, ya que colindan con el territorio, pero este sector de la economía se ubica más en el casco urbano de la cabecera municipal.

\section{Ámbito Político}

Como lo explica Gloría Ocampo (2014), el sistema político basa su pirámide jerárquica en una política de parentesco, donde se presenta un régimen de herencia, para preceder el poder. Esas grandes familias cimentaron una política, difícil de permear, con el fin de proteger su capital político. Este es el caso de Tierralta, donde hay unos grupos familiares ya establecidos que dirigen junto con los actores del territorio las dinámicas que allí se presentan.

Tanto el departamento como el municipio, siguen la tendencia del partido liberal. Su política ha estado marcada por los intereses que el partido tiene sobre la región y, por lo tanto, ha logrado consolidar una tradición política familiar. El parentesco y la consanguinidad se vuelven unos requisitos necesarios para ser partícipes de esta política.

Las facciones liberales, hacen parte de un mecanismo que tiene elementos legales e ilegales, sin que esto represente un caos dentro del 
territorio, simplemente hace parte de las dinámicas que allí se realizan. Con esto no se busca dar la idea de que la política regional, sea distinta al resto del país, sino expresar las dinámicas del Estado, los elementos ilegales y de violaciones en la región, que termina siendo la representación del gran aparato estatal.

Por tal razón, las dinámicas del territorio, aunque se visibilicen caóticas, sólo hacen parte del funcionamiento político. El clientelismo o la corrupción, solo son una herramienta para obtener el poder, y así poder realizar alianzas. En el caso de Tierralta, las alianzas se dan entre las entidades estatales, el paramilitarismo, los ganaderos y las élites económicas, quienes trazan unos intereses que terminan siendo funcionales en el territorio. Este será un tema que se toca a profundidad en el desarrollo del artículo.

\section{Actores}

Para introducir el análisis de los actores que hacen parte de las dinámicas territoriales, a continuación, se identificarán y explicarán sus roles y las relaciones que tienen unos con otros. Desde los años cincuenta, se fue presentando una configuración política en el territorio, liderado por el bipartidismo que vivía el país, solo liberales y conservadores, en batallas constantes para obtener y sostener el poder de la región, generándose coaliciones familiares que conformaron un papel protagónico del político en la región.

Según la Misión de Observación Electoral, desde 1970 se detecta la presencia de las Fuerzas Armadas Revolucionarias de Colombia (FARC), en el departamento de Córdoba, con el fin no solo de apoderarse de las rutas de narcotráfico y de las dinámicas de la región, sino también para disminuir el poderío territorial del Ejército Popular de Liberación (EPL), asentándose en los territorios en los que éste se encontraba (Tierralta, Valencia y Montelibano), con los frentes 18, 36 y 58, este último localizado en el Alto Sinú, por el que se expande el Parque Nudo de Paramillo, donde se podía controlar las rutas del narcotráfico que se presentaban en el Río Sinú y San Jorge. 
Durante esta época, las FARC, tuvieron que combatir por la disputa del territorio con el Ejército de Liberación Nacional (ELN), haciendo presencia en el Alto de Sinú, y obteniendo apoyo del campesinado y los estudiantes, aun así. En 1980 se presentó la llegada de la familia Castaño, lo cual disminuyó la importancia de este actor en el territorio, porque empezaron a controlar el negocio del narcotráfico y a comprar 950 haciendas con el fin de entrenar a campesinos para el ataque contra la insurgencia. ${ }^{2}$

La presencia de esta familia, conformó en la región las Autodefensas Campesinas de Córdoba y Urabá (ACCU), el cual pretendía convertirse en un aparato político-militar fuerte, apoyo del sistema político regional, que mediante el discurso logró unir los ideales del paramilitarismo con el desarrollo de la región, de igual forma se convirtió en brazo y apoyo para el Ejército Nacional, para obtener el control territorial y manejar las dinámicas del mismo. ${ }^{3}$

El partido político predominante de la región, el cual era el Partido Liberal. En 1995 se vio involucrado con el paramilitarismo, cuando se encontraron políticos de la región, como el representante de la cámara Lara Arjona y los senadores Jorge Elías y Francisco Jattin, con casos de corrupción, narcotráfico y nexos con paramilitares y envío de dinero al cartel de Cali. Por estas razones, el pueblo cordobés le quitó parte del apoyo al partido. Para parar esta problemática, se ingeniaron dos estrategias, la primera fue aliarse al partido de la $\mathrm{U}$ y la otra fue reforzar los lazos con el paramilitarismo para ganar las elecciones.

Estas dinámicas, lo único que generaron es que aumentara la vulneración de los derechos del campesinado, que se tuvieron que enfrentar a la disputa territorial de los actores armados, que durante la época de los 80 y 90, generaron desplazamiento, por las zonas estratégicas para el combate, rutas de movilidad y por un actor de gran relevancia en la región como son los terratenientes, que con ayuda paramilitar buscaban la ampliación de la frontera ganadera, según la prensa nacional. ${ }^{4}$

2. Información obtenida de, Monografía Político Electoral departamento de Córdoba 1997 a 2007.

3. Información obtenida, del libro Democratización política y contrarreforma paramilitar en Colombia, de Romero Vidal, (2000) en la pág. 350.

4. Ver www.elheraldo.co en https://goo.gl/1X6rMj 
Durante la época de los noventa, surgió la construcción de la hidroeléctrica Urrá I, la cual perjudicó a la comunidad Indígena EmberaKatío, que ya estaba enfrentando las dinámicas negativas del conflicto armado, y que desde 1970, tuvo que asumir las consecuencias de la represa, en cuestión de desplazamiento, medio ambiente, la destrucción de sus dinámicas regionales y la violación de sus derechos humanos fundamentales, como es el caso de la vida.

Habiendo realizado esta breve descripción de las características de los principales actores, involucrados en las dinámicas político - sociales, en el territorio. A continuación se observará la historia de la construcción de la hidroeléctrica y sus repercusiones, para dar inicio al tema central del artículo.

Desde esta perspectiva, se trazará un esquema para explicar a profundidad lo que se presentó en la introducción y que son de carácter analítico. En el primer subtema, se explicará cómo eran las dinámicas del territorio de los Embera-Katio y como afectó la construcción de la hidroeléctrica en la forma de vida de la comunidad indígena. En el segundo subtema se analizará el Estado local, verificando si se presentó un abandono estatal y si se infringió la normatividad con la construcción de la hidroeléctrica. En el tercer subtema se identificará el desplazamiento que se presentó en la región y la resistencia que los Embera, realizaron ante estas problemáticas. En el último subtema se hablará sobre las alianzas e intereses que hicieron los actores de la región. Al respecto se mirarán los mecanismos con los que lograron establecer un dominio y poderío en la región. Y al finalizar se darán las conclusiones. Con esta ruta, se pretenderá responder a la pregunta ¿Cuál es el papel y la caracterización misma del Estado real, nacional y local de frente a los intereses que se ciernen sobre un territorio nacional, y específicamente, sobre un territorio étnico?

\section{La vida del Río Sinú: Antes y Después}

Los Embera-Katío, habitan en el Alto de Sinú y en el río San Jorge, en el departamento de Córdoba y parte de Urabá, en Colombia. Su patrón de poblamiento siempre ha estado relacionado con la migración, ya que 
primordialmente vienen del Chocó, Ecuador, Antioquia y Panamá. Pero dependiendo de la categoría social y espiritual habitan en distintos lugares. Ellos generan un vínculo con el ecosistema, volviéndolo un tema cultural y de gran importancia.

Históricamente se han organizado por familias, donde el líder es el abuelo. Aun así, desde que se creó la Ley 89 en 1890, ${ }^{5}$ el cabildo instauró la nueva organización jerárquica de la comunidad, donde el liderazgo se centra en los cabildos "las comunidades eligen los cabildos locales y sus equipos y éstos luego eligen al Cabildo Mayor. Dentro del equipo hay personas delegadas para el control de los temas de explotación de madera y los recursos naturales, para dirigir el consejo territorial, para educación y para organización" (Observatorio Étnico Cecoín, n.d, p. 5).

Dentro del esquema de organización social, los hombres son los que realizan las labores de caza y siembra. Mientras las mujeres se encargan del cuidado de los niños, junto con la realización de pesca artesanal. Aun así, todos deben velar por la conservación del territorio. Poseen una gran conexión con la naturaleza. Su mito fundacional es alrededor del agua, ya que ellos consideran que de allí provienen. Y buscan proteger el ecosistema para ellos y para los que no son indígenas, ya que allí comienza la vida, como ellos lo proclaman. Por tal razón, es pertinente analizar sus funciones en cada territorio en el que habitan y sus actividades en estos.

Los Embera-Katío, tienen dividido su territorio en tres lugares,${ }^{6}$ en los cuales brindan un cuidado especial, para la preservación del medio ambiente. En el primero se encuentran zonas de reserva, denominados los prohibidos, como los cementerios y sitios de origen, en los cuales no se puede realizar actividades de caza, recolección o tala de madera, pues son considerados lugares habitados por los creadores. En el segundo se encuentran los lugares encantados, en los cuales se debe pedir permiso para entrar a los seres espirituales mediante rituales de purificación, como lo son el Río San Juan, Río Baudó, Río San Jorge y el Río Atrato. Por último, se encuentran los

5. Ver www.alcaldiabogota.gov.co en https://goo.gl/GhJjNh

6. Ver www.coljuristas.org en https://goo.gl/LxQVFC 
espacios comunales, que son las áreas destinadas para la comunidad, para desarrollar las actividades productivas, como son los Tambos, sitios de pesca, cacería y recolección de frutas.

Todos los lugares anteriormente nombrados se expresan en gran parte del parque Nudo de Paramillo. En el comunal se mueve la economía de los Embera, donde se puede realizar la pesca, el sembrado, la recolección de frutas, la cacería. En los lugares encantados se encuentra el Río San Jorge, que conecta con el Río Sinú, que son lugares sagrados junto a los prohibidos donde se debe velar por su cuidado. Aunque los Embera realizan un gran esfuerzo para proteger su proyecto de vida, existen varias dinámicas en el territorio que han imposibilitado esta acción, como es el caso del conflicto armado.

Un ejemplo de lo descrito arriba es el caso de los cultivos ilícitos, la ganadería extensiva, la siembra de minas anti-personas, que amenazan la integridad territorial del pueblo Embera, no solo porque con ello trae la presencia de otros actores sino porque traslada el conflicto a la vida del pueblo indígena, imposibilitándoles el derecho a la movilidad, al cuidado del medio ambiente, a su propia subsistencia y a su autonomía como comunidad.

Por lo tanto, los actores que predominaban en el territorio, formaron del parque Nudo de Paramillo, una disputa por la tierra y sus recursos; por una parte los ganaderos, queriendo realizar una deforestación para poder tener más ganado, para los grupos armados ilegales, manejar las rutas del narcotráfico y del territorio, ya que al ser una zona montañosa, se convierte en un frente difícil de atacar, lo cual resulta estratégico para la guerra. Un ejemplo de ello es el paramilitarismo, que utiliza el parque para generar su accionar en Urabá y en las Sabanas de Córdoba y Sucre, que limitan con el parque.

La extensa zona de Paramillo se convierte en área de importancia estratégica en lo militar, allí se localiza el centro de expansión del proyecto paramilitar, a la vez que la guerrilla y el Ejército Nacional la convierten en escenario de confrontación. Ante la situación los Embera-Katío realizaron 
la Declaración de Sambudo, ${ }^{7}$ documento en el que se buscaba tener a la comunidad indígena al margen del conflicto.

Otro actor relevante que entró en el territorio y que cambió la dinámica de la comunidad indígena, fue la hidroeléctrica Urrá I, la cual se concretó como proyecto en 1971, cuando se realizaron los primeros estudios con el fin de formalizar el mega proyecto con la empresa Interconexión Eléctrica S.A (ISA), y Damey Morre, empresa estadounidense, la cual se encargaría de la evaluación ambiental. Sin embargo, no se realizó la consulta previa, ${ }^{8}$ que por ley debe proceder antes de cualquier construcción en territorios indígenas.

Para empezar con la respectiva obra, el proyecto fue entregado a la Corporación Regional de Energía Eléctrica de la Costa Atlántica (CORELCA), empresa que contrató con la compañía rusa V.O. Energomachexport, la cual diseñó, suministró y realizó el montaje del equipo hidroeléctrico. Para esta etapa el gobierno declaró el área en la que estaba situada la construcción como utilidad pública, por los beneficios que en teoría traería este proceso de desarrollo.

Desarrollo, que rompió con la forma de vida de los Embera-Katío, que incumplió con la normatividad nacional y con el ordenamiento legal internacional el cual Colombia ratificó, con la firma del Convenio 169 de la Organización Internacional del Trabajo (OIT), el cual explica que:

"los gobiernos deberán asumir la responsabilidad de desarrollar, con la participación de los pueblos interesados, una acción coordinada y sistemática con miras a proteger los derechos de esos pueblos y a garantizar el respeto de su integridad. Esta acción deberá incluir medidas: que aseguren a los miembros de dicho pueblo a gozar, en pie de igualdad, de los derechos y oportunidades que la legislación nacional otorga a los demás miembros de la población" ("Corte Constitucional de Colombia”, 2017, Artículo 2).

\footnotetext{
7.Ver en Plan de vida Cabildos mayores Río Verde y Río Sinú, (2007) en la pág. 10.

8. La consulta previa se debe realizar cuando sea susceptible de generar afectación directa en pueblos indígenas o comunidades afrocolombianas en su calidad de tales. La corte ha intentado precisar esta regla al afirmar que hay afectación directa cuando la ley "altere el estatus de una persona o comunidad, bien sea porque le impone restricciones o gravámenes, o, por el contrario, le confiere beneficios"... la corte también ha especificado los momentos en los que debe llevar a cabo la consulta previa de medidas legislativas" (Rodríguez Garavito \& Orduz Salinas, 2012).
} 
Y aunque este convenio se ratificó en la ley 21 de 1991, el Instituto de Recursos Naturales Renovables (INDERENA), que para esa época cumplía con las tareas del Ministerio de Ambiente. Otorgó las licencias ambientales para el proyecto, comenzando así con el llenado del embalse y con el detrimento de la comunidad Embera-Katío, de sus hogares, de su forma de vivir, pero sobre todo de su relación con el espacio, con el agua, el bosque, la selva y los animales.

Para el año 2000, la hidroeléctrica entró en funcionamiento, hecho que transformó aspectos relevantes de la comunidad, como el manejo del territorio, la soberanía alimentaria, la relación del indígena con la tierra y obstaculizó el fortalecimiento de la cultura Embera. De igual forma "demandó la salida de 5.900 personas que se encontraban en cuatro asentamientos nucleados (entre ellos Tucurá, Frasquillo y Buenos Aires) y 17 dispersos para llenar el embalse." (Negrete, 2007: 3), reasentándolas en otras partes del territorio con condiciones desfavorables.

Los impactos generados por la hidroeléctrica, afectaron varios ámbitos focales para el territorio, como es el caso del agua, ya que generaron el estancamiento del Río Sinú y parte del Río San Jorge, que si bien tenían el objetivo de parar las inundaciones que se daban en época de invierno, terminó por quitarles el sustento a la comunidad indígena, ya que estos no pudieron realizar la pesca artesanal.

De igual forma se vio afectada la fauna, ya que con el llenado del embalse se disminuyó la fauna silvestre y a la vez se presentó una alteración en las cadenas tróficas, ya que con este llenado no solo no se pudo seguir consumiendo el pescado, sino que hubo una disminución de éste, específicamente del bocachico, porque al estancar el agua no se pudo seguir presentando su reproducción.

A nivel del uso del suelo, se presentó una pérdida de áreas fértiles, ya que para la construcción de la hidroeléctrica se inundaron un porcentaje de tierras para el embalse, a pesar de que Tierralta una de las tierras con los suelos más fuertes están ubicadas en el Parque Nudo de Paramillo, lo cual no solo desplazó a parte de la comunidad indígena, sino que perjudicó la siembra que venían haciendo los Embera y el campesinado.

Con todos estos agravantes, el pueblo Embera-Katío, tuvo que realizar 
un abandono paulatino a su economía tradicional, perdió los lugares sagrados, se generó una desestructuración social y cultural, y afrontaron una crisis alimentaria, lo que los llevó a desconfiar de los intereses de la hidroeléctrica y de las instituciones del Estado.

Como se puede observar, la hidroeléctrica no muestra algún balance positivo. Aun así es importante resaltar los beneficios que se propusieron con la construcción de la represa, el principal y fin primordial de la hidroeléctrica fue la generación de energía, tema que no se encontraba en déficit, sino en superávit ya que durante el periodo presidencial de César Gaviria Trujillo (1990-1994), se presentó un gran apagón a nivel nacional, por lo que se le conoció como la "Hora Gaviria", hecho que provocó que se llevaran a cabo varias construcciones de hidroeléctricas, como lo fueron "Tebsa, Termoflores en Barranquilla, Termocartagena, Miel I y II, Porce I y II, mantenimientos en Termoguajira" ("Semanario Virtual Caja de Herramientas", 2017: 1) para subsanar la problemática de energía del país. Por tal razón, no era necesaria la construcción de la hidroeléctrica Urrá I, para no generar el estancamiento de 7.400 hectáreas para producir 340 megavatios (Lozano y Osorio, 1999:32).

\section{¿Abandono o acción Estatal?}

El Estado es como lo explica Max Weber (1991), en su libro El Político y el Científico, un acto de dominación, donde una jerarquía ya establecida busca controlar al otro mediante una violencia legítima, es su función principal para poder subsistir, necesita que los demás le sean obedientes y que a la vez cumplan con unas obligaciones ya establecidas que él mismo impuso y así sus instituciones que se encuentran desplegadas en el territorio se asemejen a este.

Como se puede observar el objetivo del Estado local, es realizar una representación dominante con el fin de que la violencia que se ejerza sea legítima y cumpla con los ejercicios de autoridad sobre el territorio. Por tal razón, la construcción de la hidroeléctrica Urrá I representa las dinámicas de una imposición estructural e institucional que logra dentro de los objetivos económicos y de desarrollo desarticular un tejido social, rompiendo con las 
dinámicas de los Embera-Katío, para así ejercer con plenitud las políticas públicas que van acorde con sus intereses.

Este tipo de políticas, pueden tener la influencia de otros actores del territorio, esto significa que la maquinaria política requiere para su subsistencia alianzas que se vinculen a esas decisiones políticas para lograr los objetivos, como por ejemplo, el paramilitarismo en Tierralta durante la construcción de la hidroeléctrica, en el que se presentaron intereses económicos y políticos que llevaron al asesinato de los líderes de los Embera-Katío. Aquellos se encontraban en proceso de lucha por la reivindicación de los derechos violados y fueron acusados de pertenecer a la guerrilla. Es ahí en donde se puede observar el papel del Estado colombiano en esta violencia, un apoyo activamente a las fuerzas paramilitares como sus proxies contrainsurgentes (Serje, 2005).

Varios autores precisan los hechos de desplazamiento, conflicto armado y las dinámicas territoriales como una consecuencia del abandono estatal, como es el caso de Luis Eduardo Pérez Murcia, en su texto una mirada empírica a los determinantes del desplazamiento forzado en Colombia, de María Adelaida Ceballos Bedoya en su texto El desplazamiento forzado en Colombia y su ardua reparación (2013), de William Ortiz Jiménez en su texto Los Paraestados en Colombia (2006). En los que se busca demostrar que gracias a que el Estado no ha estado presente para cumplir con las dinámicas de una democracia, han llegado los grupos al margen de la ley, entre otros actores que han podido controlar el territorio, y que es el aparato estatal el que ha dejado los territorios a su suerte, a nivel de educación, salud, vivienda, transporte, seguridad, alimentación, etc.

Aun así son estas alianzas, las que nos muestran el accionar del Estado local y de las dinámicas que se establecen en la región, que demuestran que no hay diferencia entre un político y los gamonales, porque se utilizan las mismas prácticas de trampa y corrupción, que se dan gracias a las relaciones con los grupos armados y entes privados. Ejemplo de esto, son las violaciones que se realizaron contra los Embera, para suplir los intereses de los actores de la región, como se observará a continuación, con los derechos que están consagrados en la carta magna y que por la construcción de la hidroeléctrica y los intereses de algunos actores se pasaron por alto. 


\section{Tabla 1.}

Normativa para el proceso de construcción de la hidroeléctrica

\begin{tabular}{|c|c|c|}
\hline Normatividad & Teoría & Práctica \\
\hline $\begin{array}{l}\text { Artículo } 15 \text { de la } \\
\text { Ley } 21 \text { de } 1991 .\end{array}$ & $\begin{array}{l}\text { [Explica que] "Los derechos de los pueblos interesados } \\
\text { a los recursos naturales existentes en sus tierras deberán } \\
\text { protegerse especialmente. Estos derechos comprenden } \\
\text { el derecho de esos pueblos a participar en la utilización, } \\
\text { administración y conservación de dichos recursos. En } \\
\text { caso de que pertenezca al Estado la propiedad de los } \\
\text { minerales o de los recursos del subsuelo, o tenga derechos } \\
\text { sobre otros recursos existentes en las tierras, los gobiernos } \\
\text { deberán establecer o mantener procedimientos con miras a } \\
\text { consultar a los pueblos interesados, a fin de determinar si } \\
\text { los intereses de esos pueblos serían perjudicados, y en qué } \\
\text { medida, antes de emprender o autorizar cualquier progra- } \\
\text { ma de prospección o explotación de los recursos existentes } \\
\text { en sus tierras" ("Consulta de la Norma:", 1991). }\end{array}$ & $\begin{array}{l}\text { Por lo tanto es un derecho de los indíge- } \\
\text { nas Embera-Katío velar por la adminis- } \\
\text { tración y conservación de los territorios } \\
\text { donde habitan, en este caso el Parque } \\
\text { Natural del Paramillo, donde el recurso } \\
\text { hídrico que está en manos del Estado } \\
\text { es utilizado por la hidroeléctrica para } \\
\text { la creación de energía. Pero para esto } \\
\text { se debió realizar la consulta previa con } \\
\text { la comunidad indígena, y así evitar los } \\
\text { perjuicios que se llevaron a cabo contra } \\
\text { los indígenas generando una ruptura de } \\
\text { tejido social en el territorio. }\end{array}$ \\
\hline $\begin{array}{l}\text { Artículo 63. Ca- } \\
\text { pítulo } 2 \text { (De los } \\
\text { derechos socia- } \\
\text { les económicos } \\
\text { y culturales). } \\
\text { Constitución } \\
\text { política de } \\
\text { Colombia. }\end{array}$ & $\begin{array}{l}\text { "Los bienes de uso público, los parques naturales, } \\
\text { las tierras comunales de grupos étnicos, las tierras de } \\
\text { resguardo, el patrimonio arqueológico de la Nación y } \\
\text { los demás bienes que determine la ley, son inalienables, } \\
\text { imprescriptibles e inembargables" ("Constitución Política } \\
\text { de Colombia", 1991). }\end{array}$ & $\begin{array}{l}\text { Esto quiere decir que el parque donde } \\
\text { habitan los Embera-Katío no está a } \\
\text { disposición de la hidroeléctrica porque } \\
\text { estos bienes son inalienables. Por } \\
\text { lo tanto, este territorio no puede ser } \\
\text { utilizado por terceros, porque debe estar } \\
\text { protegido por la nación y no se puede } \\
\text { desterrar a las comunidades indígenas de } \\
\text { este territorio. }\end{array}$ \\
\hline $\begin{array}{l}\text { Artículo } 11 . \\
\text { Capítulo } 1 \text { (De } \\
\text { los derechos } \\
\text { fundamentales) } \\
\text { Constitución } \\
\text { Política de } \\
\text { Colombia. }\end{array}$ & $\begin{array}{l}\text { "El derecho a la vida es inviolable" (“Constitución Políti- } \\
\text { ca de Colombia”, 1991). }\end{array}$ & $\begin{array}{l}\text { Por esta razón, es una violación a este } \\
\text { derecho el asesinato de los líderes } \\
\text { Embera-Katío. El Estado no salvaguardó } \\
\text { la vida de éstos dentro de un territorio } \\
\text { en conflicto con los paramilitares, que } \\
\text { terminaron asesinando a los indígenas, } \\
\text { según entrevista que la Comisión } \\
\text { Colombiana de Juristas (2013) realizó } \\
\text { al Jefe paramilitar Salvatore Mancuso, } \\
\text { donde afirmó que se había realizado } \\
\text { este asesinato, porque los líderes en } \\
\text { especial Kimy Pernia9 eran "infiltrados } \\
\text { subversivos". }\end{array}$ \\
\hline $\begin{array}{l}\text { Artículo } 12 . \\
\text { Capítulo } 1 \text { (De } \\
\text { los derechos } \\
\text { fundamentales) } \\
\text { Constitución } \\
\text { Política de } \\
\text { Colombia. }\end{array}$ & $\begin{array}{l}\text { "Nadie será sometido a desaparición forzada, a torturas } \\
\text { ni a tratos o penas crueles, inhumanos o degradantes" } \\
\text { ("Constitución Política de Colombia", 1991). }\end{array}$ & $\begin{array}{l}\text { Este tipo de violaciones realizadas por } \\
\text { parte del Estado, con ayuda de los acto- } \\
\text { res anteriormente nombrados, generó un } \\
\text { incumplimiento en la labor del Estado } \\
\text { a nivel normativo. Como lo explica la } \\
\text { teoría, éste debe velar por la seguridad } \\
\text { y tranquilidad de las comunidades } \\
\text { indígenas; aun así, las dinámicas que } \\
\text { se presentan en el territorio distan de la } \\
\text { teoría a la práctica estatal. }\end{array}$ \\
\hline
\end{tabular}

Fuente: Constitución Política de Colombia", 1991

Elaborado por: la autora 
El no cumplimiento de la normativa, no representa el abandono estatal en la región, sino que expresa el accionar de este, por medio de la permisividad, al no garantizar los derechos de los pueblos indígenas.

Desde esta perspectiva, se puede observar que esta herramienta sí fue funcional para el actuar Estatal en la región. Y aunque la Corte Constitucional con la sentencia T-652 de 1998, obliga a la hidroeléctrica de Urrá I, a detener el llenado del embalse, hasta que no se realizara el trámite de consulta previa con los indígenas, cabe aclarar que el proceso de la consulta se debe realizar antes de la construcción de este tipo de proyectos, y no después. Ello no solo desata la problemática que se ha presentado en este artículo sino que revela la ineficacia institucional.

Ante esta problemática, se crearon movimientos que no solo exigían la creación de nuevas políticas, sino también la reivindicación de los derechos fundamentales que se encuentran consagrados en la constitución de 1991, y que no han sido garantizados por parte del Estado. En otras palabras, no se encuentra un bien común sino intereses estratégicos, por tal razón es fundamental hablar no solo de la masacre de los líderes de la comunidad, sino también de los procesos de desplazamiento y resistencia.

\section{Desplazamiento y Lucha de los Embera}

Los intereses privados, extranjeros y nacionales, están en constante búsqueda de los recursos naturales que se puedan explotar, aun así durante este proceso, se generan vulneraciones, al medio ambiente, al ser humano, y a las comunidades. Los indígenas han tenido que enfrentarse a quienes pretenden no sólo apropiarse de sus territorios, sino también utilizar sus recursos naturales, comercializar su arte y su experiencia en cuanto a la agricultura y

9. "Vocero valiente del pueblo emberá... se opuso a la destrucción de su tierra en el Nudo de Paramillo y a la entrada de guerrillas y paramilitares, cuando fue secuestrado por un comando paramilitar en 2001, que luego lo asesinó. Kimy era un hombre muy crítico. Fue el gestor de la primera ordenanza del Cabildo Mayor, que suspendió el corte de madera con fines comerciales. Sus posiciones radicales sobre la protección del ambiente lo llevaron a participar en la ocupación de la Embajada de Suecia en 1996, llevada a cabo por los Embera para denunciar el incumplimiento de los compromisos de la empresa Urra tras en Do Wambura [que en su lengua significa en último viaje por el Sinú]" ("La historia detrás del 'Pacto de Ralito", 2017). 
el ambiente (Houghton, 2008), lo cual no solo ha traído problemáticas para el reconocimiento de su cultura, sino que también ha generado desplazamiento y destrucción al ecosistema.

Este es el caso de los Embera-Katío, un pueblo que se esfuerza por la defensa de su territorio, mientras los intereses de empresas nacionales, extranjeras, el Estado y los ilegales buscan sacarle provecho de su riqueza, de una forma impuesta, con violaciones a los derechos humanos, desplazamientos, con el rompimiento de tejido social, quitándoles su autonomía. Por tal razón, es importante analizar los proceso de desplazamiento, que se han presentado en Tierralta, durante los años que se dio y se estableció la hidroeléctrica UrráI, como espacio temporal del artículo.

\section{Gráfico 2.}

Número de indígenas Embera Katio desplazados en Tierralta durante (19932001)



Fuente: Registro Único de Víctimas (RUV) | RNI - Red Nacional de Información”, n.d. Obtenida de http:// rni.unidadvictimas.gov.co/RUV

Elaborado por: la autora.

Como se puede observar hay un escalonamiento en el año 1996, y se presenta básicamente por el fortalecimiento de las Autodefensas Unidas de Colombia (AUC). Allí entraron en disputa con las FARC y ELN por las rutas del narcotráfico, por las zonas de Fresquillo y Campo Bello, donde se estaba dando la construcción de la hidroeléctrica. 
Para 1997, se presenta un apaciguamiento, no porque el conflicto armado y la construcción de la hidroeléctrica se hayan estancado, sino porque se presentó un acuerdo entre la hidroeléctrica para realizar la consulta previa, ${ }^{10}$ en vista de que la Corte Constitucional obligó a la hidroeléctrica a realizar un pago a la comunidad por los daños causados.

Aun así, su identidad colectiva fue transformada, llevando a los Embera a un rol de consumidores individuales en la economía de mercado, ocasionados por "los fondos precarios pero esenciales de la indemnización. Este proceso de mercantilización, individualización y pauperización de la identidad ha sido acompañado del efecto de desplazamiento jurídico señalado" (Rodríguez Garavito, 2012: 12), tema que afecta la supervivencia cultural de la comunidad, no solo porque divide a los cabildos, sino también genera una alarma de riesgo a futuro, ya que por medio de esa indemnización los Embera, podrían terminar aceptando la expansión total de hidroeléctrica en sus territorios.

Desde 1998 se ve un escalonamiento importante del desplazamiento. Esto se debe a varias cosas. La primera es que, con los problemas que trajo consigo la decisión de la corte y las violaciones a este pueblo, la comunidad indígena se vio expuesta a desapariciones, amenazas y asesinatos de sus líderes, como (Jarupia Domicó, Kimi Pernía Domicó y Augusto Lana Domicó). A continuación se observarán algunos casos que se presentaron en la comunidad durante los años 1998 a 2001.

Como se puede observar en la tabla $\mathrm{N}^{\circ} 2$ se realizaron varios procesos durante estos años, sin estos ser los únicos, pero si unos de los más relevantes con respeto a la comunidad indígena. No hay investigaciones, ni informes de la Fiscalía o de la Defensoría del Pueblo, que afirmen una alianza entre la hidroeléctrica Urrá I y el paramilitarismo en Córdoba. Aun así en el documento de los indígenas llamado Las Violaciones de los derechos humanos

10. La Corte Constitucional se pronunció con la sentencia T- 652 de 1998, en la que obligaba a la hidroeléctrica de Urrá I, a detener el llenado del embalse, hasta que no se realizara el trámite de consulta previa con los indígenas. Expresamente la sentencia decía que debía darse una compensación económica durante veinte años, mientras los Embera-Katío se acomodaban a su nueva forma de vivir ("Sentencia T-652/98", 1998). 
del pueblo Embera Katío del Alto Sinú, realizado después de la audiencia por la vida y la autonomía, en el año 2001, manifestaron que su problemática estaba asociada a dos factores, al conflicto armado y a los diferentes intereses a nivel internacional, nacional y regional, asociados con el megaproyecto (Acnur, n.d).

\section{Tabla 2.}

Casos de Violaciones, Amenazas y Despojo

\begin{tabular}{|l|l|}
\hline \multicolumn{1}{|c|}{ Fecha } & \multicolumn{1}{c|}{ Casos } \\
\hline 12 de Julio de 1998 & $\begin{array}{l}\text { Se hicieron amenazas a seis miembros de las comunidades del Río } \\
\text { Sinú y Verde, se quemó la canoa de la comunidad indígena. Este acto } \\
\text { fue realizado por el paramilitarismo. }\end{array}$ \\
\hline 24 de Abril de 1999 & $\begin{array}{l}\text { Se queman varias embarcaciones de la comunidad indígena y es } \\
\text { asesinado el líder Alejandro Domicó. Este acto fue realizado por el } \\
\text { paramilitarismo. }\end{array}$ \\
\hline Septiembre de 2000 & $\begin{array}{l}\text { Asesinan al líder indígena Lucindo Domicó, el cual desempeñó un } \\
\text { hidroeléctrica Urrá I. Este acto fue realizado por el paramilitarismo. }\end{array}$ \\
\hline himpontan & $\begin{array}{l}\text { Los paramilitares ordenaron a parte de población del Llano, en lími- } \\
\text { tes con Antioquia, y les ordenaron el "despeje del área", advirtiendo } \\
\text { que aquellas personas que no lo hicieran serían consideradas miem- } \\
\text { bros de la guerrilla. Además, no respetarían el territorio indígena, y } \\
\text { contaban con un grupo de hombres para incursionar en el territorio. }\end{array}$ \\
\hline Junio de 2001 & $\begin{array}{l}\text { Se encuentra el registro de 17 asesinatos de personas indígenas } \\
\text { Embera-Katío. }\end{array}$ \\
\hline
\end{tabular}

Fuente: Informe de defensoría presentado por el Defensor Delegado para Indígenas y Minorías Étnicas. Obtenido en http://www.acnur.org/t3/uploads/pics/2461.pdf?view=1

Elaborado por: la autora.

El rol estatal, no solo se presentó en las dinámicas de conflicto, del gamonalismo, y de su no acción como garante de los derechos humanos de la comunidad indígena, que se convirtió en su actuación local, influenciado por alianzas e intereses regionales. Sino también en la construcción de la hidroeléctrica de Urrá I, y de las acciones que se presentaron desde el Estado, para el desplazamiento y usurpación de las tierras que fueron inundadas para el llenado del embalse de la represa. 
Los Embera-Katío, buscaron resaltar la problemática, realizando actividades y movilizaciones como el caso del Do Wabura o adiós río, donde aproximadamente 660 indígenas navegaron en balsas por el Río Sinú, para mostrarle al país sus dinámicas, su cosmovisión que se perdería sino se llegaba a soluciones reales y profundas con el daño que ocasionaba la represa.

Aun así, las entidades estatales obviaron la importancia de los EmberaKatío en el territorio, y de la normatividad que los protege a ellos. El Centro de Memoria Histórica, en su informe "la tierra en disputa" realizó entrevistas, a exfuncionarios del Incora, donde relataron las acciones que llevaron a cabo, para que la construcción de la hidroeléctrica fuera un éxito.

Una de las entidades estatales, más relevantes sobre el tema de tierras, como lo es el Instituto Colombiano de la Reforma Agraria (INCORA), tuvo un plazo por parte de las entidades que trabajaban para la construcción de la hidroeléctrica, de desocupar las tierras del Alto Sinú, un aproximado de 6,400 hectáreas, para empezar con gran parte de la inundación para el llenado del embalse de la represa, y así la construcción se apresurara, para dar funcionamiento lo antes posible.

También el instituto tenía que encargarse de las tierras que no tenían títulos, para que estas fueran adjudicadas a las personas que la hidroeléctrica Urrá propusiera, terrenos que fueron utilizados por Mancuso, según las afirmaciones de los exfuncionarios. Algunos indígenas y campesinos de esta zona fueron reasentados en tierras, que para algunos resultaron poco fértiles, otros fueron desplazados y otra parte abandonó las tierras por los acosos y amenazas que recibían de los grupos al margen de la ley.

Desde esta perspectiva se puede observar que actores del territorio, y el Estado, estaban realizando una presión para que el proyecto pudiera estar en funcionamiento lo más pronto posible. Ahora, ¿Qué tan importante era Urrá I, para el país? Si varios analistas afirmaban que había varias hidroeléctricas que podían suplir el trabajo de esta represa y otros por el contrario decían que solo representaba 340MW y que no era suficiente porque el país necesitaba 12.000MW según el Observatorio Social de Empresas Transnacionales, Megaproyectos y Derechos Humanos de Colombia. Si bien, las dos posturas 
pueden tener algo de razón, queda la duda de cuál fue el propósito fundamental para la construcción.

\section{Alianzas e Intereses}

Como se pudo observar en el subtema anterior, las acciones de las entidades estatales, muestran unos intereses más allá de la creación de energía del país, por tal razón es importante analizar los verdaderos intereses, que aunque no han sido analizados a profundidad por las entidades públicas, sí son demandas de las organizaciones sociales y de la propia comunidad Embera-Katío.

\section{Tabla 3.}

Los verdaderos Intereses

\begin{tabular}{|l|l|}
\hline \multicolumn{1}{|c|}{ Interés } & \multicolumn{1}{c|}{ ¿Por qué? } \\
\hline $\begin{array}{l}\text { Dominio } \\
\text { Territorial }\end{array}$ & $\begin{array}{l}\text { La construcción de la hidroeléctrica permitía el dominio absoluto del para- } \\
\text { militarismo en esa parte de Córdoba y Urabá, que garantizaba la expansión } \\
\text { de los dos crecientes frentes económicos, en esas tierras que son: la ganade- } \\
\text { ría y el sector minero. }\end{array}$ \\
\hline $\begin{array}{l}\text { La presencia } \\
\text { de las FARC- } \\
\text { EP y los } \\
\text { Paramilitares }\end{array}$ & $\begin{array}{l}\text { Con el fin del exterminio de los Embera-Katío del territorio, se acusaron a } \\
\text { los líderes de ser aliados de la guerrilla. El jefe paramilitar Carlos Castaño, } \\
\text { que hacía favores a granel al gobierno y a la clase política de Córdoba, } \\
\text { reconoció que la muerte de Alonso María Jarupia, venerable autoridad tra- } \\
\text { dicional de la comunidad de Kiparado (Cruz Grande), "había sido a todas } \\
\text { luces un asesinato" y manifestó que él no iba a seguir haciéndole mandados } \\
\text { a Urrá. }\end{array}$ \\
\hline Tierra Fértil & $\begin{array}{l}\text { Los senadores de Córdoba, Sucre, César y Antioquia (Salomón Nader, Julio } \\
\text { Manssur, Julio César Guerra, Mario Uribe y Álvaro Uribe) tenían grandes } \\
\text { intereses por la fertilidad de esas tierras. Presionando así al entonces } \\
\text { ministro de Medio Ambiente Juan Mayr, para que expidiera la licencia de } \\
\text { funcionamiento a la hidroeléctrica. Para la apropiación de tierras de los } \\
\text { Embera, que se desplazarían por el llenado del embalse y la represión del } \\
\text { paramilitarismo. }\end{array}$ \\
\hline
\end{tabular}

Fuente: Corporación Grupo Semillas. Obtenida en http://semillas.org.co/es/revista/la-represa-de-urr Elaborado por: la autora. 
Como se puede observar, Urrá fue el proyecto perfecto, para apropiarse de tierras que como se habló anteriormente, se hizo posible gracias al INCORA, al paramilitarismo y la clase política de la región. El Estado no solo dejó pasar por alto sino que también ayudó a que se generaran distintas violaciones a los Embera-Katío, alejándolos de su territorio. Por lo tanto, el proyecto era algo más que un propósito para incrementar la energía en la región.

El proyecto se planeó a tal magnitud, que se fomentó un discurso, cimentado en el desarrollo energético, ya que para los años noventa se presentaron varios apagones por insuficiencia energética, tema que ya se había tocado con anterioridad. El precepto función para que parte del país considerara el proyecto como una necesidad. Pero este discurso, no para ahí, una de las soluciones que brindaría la creación de la hidroeléctrica era que se acabarían las inundaciones que se daban en invierno por los ríos San Jorge y Sinú, porque el agua de estos estaría estancada por el embalse, aun así las tierras que se apropió la hidroeléctrica, terminaron en manos de hacendados cordobeses y antioqueños, incluido Álvaro Uribe Vélez, según Estefan Baleta López, en su informe de Los Embera-Katio: pueblo desgarrado de Colombia (2005).

Todo lo que representara resistencia, debía ser callado, burlado y menospreciado, a tal punto de no solo quitarle la autonomía al pueblo Embera, sino también destruir a los sindicatos, que se encontraban en desacuerdo, con los megaproyectos por sus condiciones laborales. Las alcaldías de la Unión patriótica, también debían ser borradas por representar a las FARC. Todo ello, con el objetivo real de apropiarse de la tierra y de las rutas del narcotráfico. Para éstos "las alianzas entre dirigentes políticos, militares activos, compañías transnacionales, empresarios y paramilitares [se construyó] para imponer un esquema" (Martínez Triviño \& Reyes Albarracín, 2012: 1), que se explicará a continuación. 


\section{Tabla 4.}

Esquema de Alianza (Estado, élites y paramilitares)

\begin{tabular}{|l|l|}
\hline \multicolumn{1}{|c|}{ Frentes } & \multicolumn{1}{c|}{ Propósito } \\
\hline Desarticular los Sindicatos & $\begin{array}{l}\text { Con el fin de imponer unas políticas laborales que estén } \\
\text { al servicio de los patronos, de las transnacionales y de los } \\
\text { mega-proyectos. }\end{array}$ \\
\hline Recuperación de Alcaldías & $\begin{array}{l}\text { Todas las que estuvieran en manos de la Unión Patriótica, mo- } \\
\text { vimientos de izquierda derivado del ala política de las FARC. }\end{array}$ \\
\hline $\begin{array}{l}\text { Incrementar la Violencia } \\
\text { como control social }\end{array}$ & $\begin{array}{l}\text { Realizar asesinatos, masacre, desapariciones forzadas, despla- } \\
\text { zamiento de todo aquello que representara resistencia. }\end{array}$ \\
\hline Rutas del Narcotráfico & $\begin{array}{l}\text { Los anteriores frentes son la prelación a la realización de este } \\
\text { último, se necesitaba tener un territorio despejado de oposi- } \\
\text { ción, resistencia y sindicatos. }\end{array}$ \\
\hline
\end{tabular}

Fuente: Revista académica de la Universidad Santo Tomas, (2013). 'Los aborígenes colombianos y las paradojas del desarrollo: el caso de los emberá katíos del Alto Sinú'. Obtenida en http://revistas.usta.edu.co/index. php/hallazgos/article/view/741

Elaborado por: la autora.

Se configura este esquema, el cual se encuentra al servicio de las élites políticas, económicas y actores armados, y que beneficia en gran parte a la hidroeléctrica, a tal punto, de considerarla en la región como una nueva institución, puesto que, los Embera-Katío depende en parte de sus decisiones $\mathrm{y}$ de las acciones que tome en conjunto con las entidades estatales.

De esta forma, la democratización queda aislada, no prevalecen los derechos fundamentales del ciudadano, sino que se genera una privatización del territorio, como es el caso del parque Nudo del Paramillo, que pasó de ser un patrimonio de la humanidad a un territorio comercial financiero. Allí los recursos están a disposición de las empresas, de las élites y de la economía ilegal, generando prácticas que destruyen el mito fundacional de las comunidades indígenas, desdibujando el plan de etno desarrollo de los Embera. Por lo tanto, el territorio se vuelve una apropiación privada (Houghton, 2008).

Así, "los beneficios económicos generados por estos megaproyectos son destinados para la élite social, los políticos corruptos y la empresa privada; los enormes impactos socioculturales, económicos y ambientales son 
la mayoría de los habitantes" (Rankin, 2002: 5). El Estado sigue pensando el "desarrollo", como un eje que debe ser más importante que las realidades del territorio, si bien el tema de la energía es importante, en el país no se invierte mucho en energía renovable, que a la final no afecta a gran magnitud el medio ambiente ni a las comunidades que habitan los territorios.

\section{Conclusiones}

Al inicio del artículo nos preguntábamos cuál era el rol del Estado local, frente a los intereses y las dinámicas que se presentan en el territorio de Tierralta, específicamente en el Parque Nudo del Paramillo por la construcción de la Hidroeléctrica Urrá I, y que afectó en gran medida a la comunidad indígena Embera-Katío.

Durante el proceso de este texto se evidenció, que Urrá I, trajo a los Embera desplazamiento, masacres, problemas ambientales, que junto con las violaciones normativas que se realizaron, solo evidencia el esquema, las alianzas y estrategias que utilizaron las élites política y económicas de la región, las instituciones del Estado y los grupos armados ilegales.

El Estado colombiano, realizó una de sus políticas públicas más grandes, impuso una hidroeléctrica para la producción de energía, a la vez promovió una pequeña reforma agraria en la que se ejecutó la titulación de predios de la comunidad indígena a ganaderos de la región, por medio de la institución del INCORA, y reubicó a una parte de los indígenas y campesinos para que estos no afectaran las dinámicas del paramilitarismo en la región, ni de los terratenientes y tampoco del funcionamiento de la represa.

Como hemos demostrado en este artículo, el Estado, igualmente llevó a cabo un acto de dominación, que gracias a las alianzas que se formaron, llevó a sus participantes a lograr sus objetivos en torno a una acumulación de capital económico y político. Como se evidenció, todo esto se hizo bien por la vía armada, por medio de corrupción, control territorial, la ruptura de tejido social que se expresó, entre otras, en las masacres y despojos que se le realizaron a la comunidad Embera-Katío. 
A nivel nacional el control y tenencia de la tierra es uno de los factores más relevantes para tener algún tipo de poder en las regiones; como se pudo observar este caso no fue la excepción. El control del territorio indígena y de las rutas del narcotráfico fueron algunos de los intereses de importancia del paramilitarismo en Córdoba, con ese fin no solo forzó a más de 30.000 habitantes de Tierralta a desplazarse, sino que también asesinó a gran parte de los líderes indígenas, mediante una campaña de imposición del miedo.

Con este despojo, la venta forzada de la tierra y la construcción de la hidroeléctrica en el territorio, las élites locales y el paramilitarismo, lograron posicionarse en miles de hectáreas, que como lo expresó la Defensoría de Pueblo, las tierras usurpadas por Urrá I, solo beneficiaron los grandes intereses de los terratenientes de la región, sin importar que la compra y adjudicación de títulos fuese de manera irregular y violenta.

Ante esta dinámica, no solo se evidenciaron los tratos corruptos entre legales e ilegales, que expresan una confabulación estatal. Las instituciones locales se aprovecharon del problema y las entidades nacionales no tomaron cartas en el asunto, a excepción de la Defensoría del Pueblo y de organizaciones internacionales como la OIT, que trataron de manifestar las violaciones que se estaban llevando a cabo con los Embera-Katío. Aun así, el tecnicismo de estas dos organizaciones no previno la masacre de nueve líderes indígenas, ni las problemáticas ambientales que la construcción de esta hidroeléctrica trajo al territorio.

El Estado falló en sus preceptos democráticos y a la sociedad. No solo por ser partícipe de las violaciones que se le realizaron al pueblo indígena. Sino también por dar carta blanca para que la represa de Urrá I, lograra posicionarse en el territorio como otro ente institucional, que se impuso a la población del Alto Sinú en Tierralta.

Este proyecto llevó al desplazamiento de los Embera, no solo por la construcción de ésta sino también, porque con los fondos que daba la hidroeléctrica a los cabildos, terminaron por desquebrajar la unión de los indígenas y le quitaron fuerza a la resistencia que venían haciendo por la imposición y los estragos que la represa generaba. 
El artículo evidenció un Estado violador de derechos humanos, que aunque con una legislación especial para las comunidades indígenas, abusó de sus funciones de poder para expropiar y quitarle autonomía a los Embera, para generar unos intereses más sectoriales que comunes, y trayendo al territorio un nuevo actor como lo es la hidroeléctrica que incrementó no solo la disputa territorial, sino también trajo consigo la violencia que ya vivenciaba la comunidad indígena.

Varios autores, con distintos argumentos y en una variedad de circunstancias del país, han demostrado que en las regiones como Córdoba y específicamente en Tierralta hay un abandono estatal, aun así, para méritos de la investigación y como se expuso durante el desarrollo del artículo, es importante resaltar, que en este hecho en específico, que puede ser relacionado con otros, se considera que no hay abandono de las entidades estatales: es el Estado, haciendo política pública, reformas agrarias, planeación de megaproyectos. No de la forma democrática que se expresa en la constitución, sino de la forma real, con las dinámicas y actores del territorio, que ya han establecido una forma de actuar y llevar a cabo el tan afamado "desarrollo", a lo local. Que muchas veces termina siendo un despropósito para los ideales de una democracia.

Deformar los mecanismos de resistencia es una de las expresiones del Estado y los actores regionales, para resaltarle a la comunidad quién es el que lleva la batuta en estas confrontaciones. Aunque se exija democracia, cumplimiento de la normativa, respeto por la vida y la autonomía de los pueblos, estos preceptos no se tomaron con la importancia que tienen, porque iban en contravía de los intereses de quienes detentan el poder en la región.

En conclusión, se ha demostrado que la teoría de abandono estatal es cuestionable y que el accionar de éste giró en torno a los verdaderos intereses particulares nacionales e internacionales que se tenían por la construcción de la hidroeléctrica Urrá I. Finalmente, el papel del Estado logró, desequilibrar los mecanismos de resistencia de los Embera, y adjudicar terrenos indígenas a otros, establecer una violencia "legítima", donde la comunidad terminó aceptando ciertas obligaciones que desquebrajaron su composición social y cultural y que terminaron por sobreponer derechos individuales sobre los colectivos. 


\section{Referencias}

Acnur. Resolución Defensorial No. 013. Recuperado de http://www.acnur. org/t3/uploads/pics/2461.pdf?view=1

Castrillón Zapata, F., Jaramillo, E., \& Mesa Cuadros, G. (2012). La represa de Urrá y los embera katio del Alto Sinú: Una historia de farsas y crímenes. - Semillas. Semillas.org.co. Recuperado 3 Enero 2017. Recuperado de https://goo.gl/H2AHoK

Comisión Colombiana de Juristas. (2013). Gente de río (pp. 15-80). Bogotá: Comisión Colombiana de Juristas. Recuperado de https:/goo.gl/ LxQVFC

Constitución Política de Colombia. (1991). Procuraduria.gov.co. Recuperado 18 Marzo 2016, de https://goo.gl/qyEGrf

Consulta de la Norma. (1991). Alcaldiabogota.gov.co. Recuperado 17 Marzo 2016, de https://goo.gl/e7dVLQ

Corte Constitucional de Colombia. (2017). Corteconstitucional.gov.co. Recuperado 21 Febrero 2017, de https://goo.gl/UvHJoV

Ecología política. (2005). Colombia. Barcelona: Icaria Editorial. Recuperado de https://goo.gl/SmvliP

El Heraldo. (2014). Campesinos reclaman las primeras 350 hectáreas en Tierralta. Recuperado de https://goo.gl/sTtEsH

Embera Katío. Observatorio étnico cecoin. Recuperado 22 Febrero 2017, de https://goo.gl/0bLqml

Houghton, J. (2008). La tierra contra la muerte (1st ed.). [Bogotá]: Centro de Cooperación al Indígena. 
Lozano V, F., \& Osorio Pérez, F. (1999). De víctimas de la violencia a constructores de vida (pp. 16-34). Santafé de Bogotá: Universidad Javeriana.

Martínez Triviño, A., \& Reyes Albarracín, F. (2012). Los aborígenes colombianos y las paradojas del desarrollo: el caso de los emberá katíos del Alto Sinú. Recuperado 5 Abril 2016, de https://goo.gl/n8ohuV

Misión de Observación Electoral. Monografía Político Electoral DEPARTAMENTO DE CÓRDOBA 1997 a 2007. Bogotá: Claudia López Hernández. Recuperado de https://goo.gl/hG02qJ

Negrete, V. (2007). “¿Hidroeléctrica de Urra II? El ejemplo de Urra I y la situación actual no lo aconsejan”. Revista Interacción, 47.

Noticias UNO, La red independiente. (2015). Ganaderos de Córdoba investigados por alianzas con paramilitares. Recuperado de https://goo. $\mathrm{gl} / \mathrm{zUba} 46$

Ocampo, G. (2014). Poderes regionales, clientelismo y Estado (1st ed.). Bogotá: ODECOFI.

Ortiz, W. (2006). Los paraestados en Colombia (Doctorado). Universidad de Granada, España.

Plan de vida cabildos mayores Río Verde y Río Sinú. (2007). Ministerio de Interior. Recuperado 22 Febrero 2017, de https://goo.gl/fYnUS7

Rankin, A. (2002). Agua y deuda ecológica. Colombia: Censat Agua Viva FoE. Recuperado de https://goo.gl/iw31Xj

Registro Único de Víctimas (RUV) | RNI - Red Nacional de Información. Rni.unidadvictimas.gov.co. Recuperado 6 October 2016, de https://goo. gl/Hs9Xya 
Rodríguez Garavito, C. (2012). Etnicidad.gov (1st ed.). Bogotá, D.C: Dejusticia Centro de Estudios de Derecho, Justicia y Sociedad.

Rodríguez Garavito, C., \& Orduz Salinas, N. (2012). Adiós río (1st ed.). Bogotá: Centro de Estudios de Derecho, Justicia y Sociedad.

Romero Vidal, M. (2002). Democratización política y contrarreforma paramilitar en Colombia (1st ed.). Universidad Complutense de Madrid, Facultad de Ciencias Políticas y Sociología.

Ruiz Serna, D. (2008). Gente de agua (1st ed.).

Ruiz, D. (2006). Nuevas formas de ser negro. Consideraciones sobre las identidades entre la gente chilapa y negra del Bajo Atrato. Colección Monografías. Caracas: Universidad Central de Venezuela. [Links].

Semanario Virtual Caja de Herramientas. (2017). Viva.org.co. Recuperado 3 Mayo 2017, de https://goo.gl/ehYn3n

Sentencia T-652/98. (1998). Corteconstitucional.gov.co. Recuperado 10 Febrero 2017, de https://goo.gl/mb5R5U

Serje, M. (2005). El revés de la nación (1st ed.). Bogotá: Universidad de los Andes.

Vilora de la Hoz, J. (2004). La economía del departamento de Córdoba: ganadería y minería como sectores clave. Banco de la República. Recuperado de https://goo.gl/xWpd2L

Weber, M. (2005). El político y el científico (1st ed.). España: Alianza Editorial. 